\title{
A guerra como espetáculo: uma reflexão sobre os conflitos militares na pós-modernidade*
}

\author{
Amanda Pinheiro Mancuso \\ Universidade Federal de São Carlos
}

Este ensaio tem como objetivo promover uma discussão sobre a guerra na sociedade pós-moderna tendo como eixo teórico o conceito de espetáculo desenvolvido por Guy Debord em sua obra "A sociedade do espetáculo". Neste livro, o autor descreve a emergência e o desenvolvimento histórico de um estágio do capitalismo que se organiza em torno de novas formas de dominação onde as imagens e os signos passam a intermediar as relações sociais, transformando a realidade em espetáculo, ou falsa realidade. Neste trabalho, analisamos a guerra como instância desse mundo espetacularizado, tomando as duas "guerras do Golfo" (1991 e 2003) como objeto de análise.

Palavras-chave: Pós-modernidade - Sociedade do espetáculo - Guy Debord - Guerra.

This essay aims to promote a discussion about war in post-modern society having as a theoretical line the concept of spectacle developed by Guy Debord in his book "La société du espectacle". In this book, the author describes the emerging and historical development of a capitalism stage established around new ways of domination where images and signs start to interpose social relations, turning reality into spectacle or false-reality. In this paper, the war is analyzed as instance of this spectacularized world, taking the two "Gulf wars" (1991 e 2003) as a manner of analysis.

Keywords: Post-modernity - Spectacle society - Guy Debord - War.

\section{Introdução}

E, contudo, Marx continua sendo infelizmente demasiado atual, quando evoca, no mesmo livro, este governo "que não toma de noite as decisões que quer executar de dia, mas decide o dia e executa à noite". (DEBORD, 1997a, p.22).

$\mathrm{N}$ os últimos anos muito se ouvir falar a palavra espetáculo, seja da vida, do crescimento e também da guerra. O conceito foi criado por Guy Debord em seu livro A sociedade do espetáculo (1967) para descrever a principal característica da sociedade pertencente à fase atual do modo de produção capitalista:

\footnotetext{
* The war as a spectacle: a reflection about military conflicts in post-modern times

${ }^{1}$ Doutora pelo Programa de Pós-graduação em Ciências Sociais da Universidade Federal de São Carlos e pesquisadora associada ao Arquivo de História Militar Ana Lagôa da Universidade Federal de São Carlos. Endereço para correspondências: Rua 23, 1451, Jardim Mirassol, Rio Claro, SP, 13503-100 (mancuso_amanda@yahoo.com.br).
} 
uma sociedade na qual as relações sociais entre as pessoas se realizam intermediadas pela imagem. Porém, a superutilização do termo espetáculo, principalmente para se referir ao que quer que diga respeito ao meio de comunicação mais marcante dessa sociedade - a televisão - fez com que ele perdesse sua essência e se transformasse em mais um chavão desse veículo de massa. Utilizado num sentido de falsa crítica ou de falsa consciência, essa "falsificação do real" talvez seja a única característica aparente que permanece ao conceito desenvolvido por Debord, pois, como tudo nessa sociedade, ele foi apropriado pela sociedade espetacular e transformou-se, como define Eco (1993), em mais um daqueles conceitos amplamente utilizados para explicar os mais diversos fenômenos, mas que, no fundo, implicam no real desconhecimento dele: o conceito-fetiche. ${ }^{2}$

Mas apesar da apropriação do conceito pelo espetáculo, no campo teórico ele continua sendo um conceito válido e atual. Como o próprio Debord fazia questão de ressaltar nos prefácios das inúmeras re-edições, o livro não sofreu nenhuma alteração no decorrer dos anos desde sua primeira publicação, apesar do rápido avanço do espetáculo, principalmente a partir da década de 80 . Debord acreditava que suas considerações permaneceriam as mesmas para além do fím do século, isto porque teria compreendido os fatores constitutivos do espetáculo "no curso do movimento e conseqüentemente pelo seu lado efêmero", quer dizer, encarando o conjunto do movimento histórico que edificou esta ordem e que agora começa a dissolvê-la. Durante este tempo, diz Debord, "o espetáculo não fez mais que unir com mais rigor o seu conceito, e o movimento real da sua negação não fez mais que propagar-se extensivamente e intensivamente" e, assim, permanecerá o livro sem a necessidade de revisão enquanto permanecerem as condições gerais desse período histórico. ${ }^{3}$ Por tudo isso, Debord deu uma grande contribuição para a análise do capitalismo no mundo pós-moderno. ${ }^{2}$ Conceitos-fetiche são conceitos genéricos amplamente difundidos e "tem a particularidade de
bloquear o discurso, enrijecendo o colóquio num ato de reação emotiva" (ECO, 1993, p.11-12), ou
seja, é como se ele fosse um esvaziamento do conceito, uma redução de seu significado real,
descolado do contexto pela utilização excessiva que acaba por torná-lo vazio. Segundo Eco, seu uso
indiscriminado implica numa incapacidade de aceitar os eventos históricos aos quais se refere.
Como ele explica, com relação ao conceito-fetiche cultura de massa:

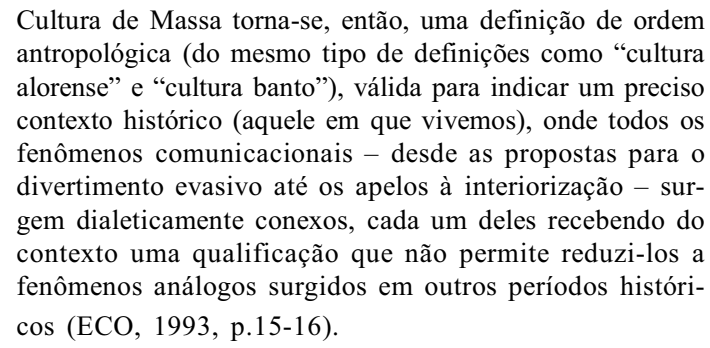
antropológica (do mesmo tipo de definições como "cultura alorense" e "cultura banto"), válida para indicar um preciso contexto histórico (aquele em que vivemos), onde todos os fenômenos comunicacionais - desde as propostas para o divertimento evasivo até os apelos à interiorização - surgem dialeticamente conexos, cada um deles recebendo do contexto uma qualificação que não permite reduzi-los a fenômenos análogos surgidos em outros períodos históricos (ECO, 1993, p.15-16).

Dessa forma, todo mundo fala em cultura de massa, aplica o termo em diversas situações como se somente o termo bastasse como explicação completa de um determinado fenômeno.

${ }^{3}$ Prefácio à Quarta edição italiana de "A sociedade do espetáculo", (DEBORD, 1997). 
O objetivo deste trabalho é discutir o conceito de Debord em uma de suas muitas aplicações atuais: o espetáculo da guerra. Desde a guerra travada em 1991 pelos EUA contra o Iraque, o conceito vem sendo utilizado para definir os modernos ataques empreendidos pela principal potência mundial, com o emprego de superarmas e a presença massiva da televisão, exibindo os bombardeios como artifício na briga pela audiência. Nesse processo, a quantidade de informação divulgada a cada minuto não prima por qualidade. Ao contrário, essa qualidade se perde em meio à enxurrada de notícias veiculadas, muitas vezes desconexas dos acontecimentos e, não raro, não condizentes com a realidade. Assim, a alienação recíproca gerada pelo espetáculo - alienação da própria realidade e da existência do espetáculo - está presente também na guerra, em que um acontecimento que atinge a vida de milhares de pessoas, provocando o sofrimento e a morte de seres humanos reais, se transforma em imagens de jogos de guerra, como aqueles disputados por crianças em seus videogames, como imagens de uma realidade que não nos atinge e é passível de ser esquecida no minuto seguinte: "A realidade surge no espetáculo e o espetáculo é a única realidade". Isto é, na guerra, o real se resume somente os fleches de luz em meio à escuridão, o que mais existe não interessa ao espetáculo, ou seja, a ninguém.

\section{Guy Debord e o espetáculo}

Antes de falarmos sobre o espetáculo, caberia levantar uma breve discussão sobre a condição responsável ou garantidora de sua existência: a pósmodernidade. Segundo Jameson (1985), este conceito é mais um dos muitos que permanecem pouco compreendidos, embora amplamente utilizado. Sua principal função é definir uma forma específica de manifestação cultural surgida nos anos posteriores à II Guerra Mundial como uma reação ao cânone da modernidade. Esse movimento, que marcou a revolução no campo cultural do começo do século XX, passou então a ser visto como o sistema a ser destruído para que algo novo pudesse surgir. Nesse sentido, sua principal característica é a quebra de velhas fronteiras culturais tradicionais, principalmente aquela que separava a cultura erudita da cultura popular. Com isso, não somente se perdeu a linha que separava uma "cultura superior" de outra "popular", entendida como tradicional, mas tudo foi apropriado por esse novo sistema e transformado em cultura popular em seu sentido pejorativo e dominador: a cultura de massa.

Portanto, a pós-modernidade é um conceito de periodização que correlaciona "a emergência de novos traços formais na vida cultural com a emergência de um novo tipo de vida social e de uma nova ordem econômica" (JAMESON, 1985, p.17) que, entre suas muitas denominações, é também conhecida como sociedade do espetáculo. Surgidos na mesma época, cada um dos conceitos estabelece seu domínio sobre diferentes aspectos da vida humana - 
econômico, cultural, social, político - e passam a definir o estilo e as condições de vida nas sociedades nas quais o capitalismo se tornou o modelo vigente, num processo iniciado a partir da II Grande Guerra.

O espetáculo é uma visão de mundo que se objetivou, se tornou concreta, e surgiu ao mesmo tempo como projeto e resultado do modo de produção que caracterizou o século XX: o modo de produção capitalista. Ele é a característica definidora da vida nas sociedades nas quais o capitalismo se apresenta em sua plena condição, transformando-as numa imensa acumulação de espetáculos, isto é, "tudo o que era vivido diretamente tornou-se uma representação" (DEBORD, 1997, p.13). Nesse estágio do modo de produção capitalista, o capital atingiu tal grau de acumulação que se desprendeu da própria mercadoria em sua forma física, transformando-se em imagem. Dessa forma, tudo o que é não somente produzido, mas também vivido nessas sociedades é transformado em mercadoria e, portanto, passível de ser consumido. Porém, o espetáculo não é somente o conjunto dessas imagens produzidas pelo capital, mas o processo no qual as imagens passam a ser as mediadoras das relações sociais entre as pessoas. Embora sejam reais tanto o capitalismo quanto a sociedade que o faz funcionar, o espetáculo transforma a vida real em irrealidade e consubstancia-se no modelo de relação social dominante da sociedade.

Segundo Debord (1997), sob todas as formas particulares de manifestação do espetáculo como a informação e a propaganda, a publicidade ou o consumo direto de divertimentos, ele se caracteriza por transformar toda a realidade do mundo em imagem. Para tanto, criou uma linguagem própria constituída pelos sinais dessa produção dominante, cujo principal objetivo é sua própria manutenção e a perpetuação do status quo. Com isso, a sociedade do espetáculo passa a ser o sinônimo do atual estágio de desenvolvimento da sociedade. Isto é, enquanto uma relação social, o espetáculo é a própria atividade social, porém agora com este novo elemento que se coloca entre as pessoas, a imagem. Ela falsifica e domina tudo, do chocolate aos ídolos, da cerveja aos ideais e pensamentos. Tudo é transformado em mercadoria. Não aquela mercadoria que mediava as relações entre as pessoas nos primórdios do capitalismo, mas sim essa nova mercadoria em forma de imagem, num processo em que as coisas não precisam exatamente ser, independente de sua existência física, basta que elas apareçam ou pareçam ser.

Como produto e projeto do modo de produção capitalista, gerador insaciável de mercadorias que se tornam objeto de desejo, devoção e sinônimo de felicidadeo fetiche da mercadoria - o espetáculo é uma forma de dominação que aparece quando, na verdade, os homens já foram totalmente dominados pela economia, pela crescente produção de "imagens-objeto", ou seja, "é o reflexo fiel da produção das coisas, é a objetivação infiel dos produtores" (DEBORD, 1997, p.24). 
Com isso, após a primeira fase da degradação promovida pelo capitalismo que transferiu a realização humana do ser para o ter, a fase atual caracterizada pelo espetáculo promoveu uma nova transferência do ter para o parecer. É esse o elemento que transforma o mundo real: uma vez que o mundo é traduzido em imagens, elas se tornam a realidade. Dessa forma, se antes a economia era o meio, na sociedade do espetáculo ela se torna o fim ao qual os homens se submetem totalmente e onde a alienação atingiu o seu ápice.

O espetáculo é, ao mesmo tempo, o gerador da produção e do consumo, criando pseudonecessidades e engendrando um processo de sobrevivência ampliada, no qual nem tudo o que é desejado é realmente indispensável à sobrevivência. É ele quem expressa o que a sociedade pode fazer - sem relação com o que é possível ser feito - promovendo a manutenção da situação estabelecida. Num processo como este, no qual tudo está previsto e determinado pelo sistema, não são dadas as condições para que as contradições inerentes ao sistema capitalista se realizem, frustrando o sonho revolucionário. $\mathrm{O}$ isolamento das pessoas no espetáculo, como tudo criado e desenvolvido por ele, não é mais que aparência e não passa de seu processo técnico, no qual ser diferente nada mais é que ser igual, uma vez que todos os bens gerados pelo sistema do espetáculo são "suas armas para o reforço constante das condições de isolamento das multidões solitárias" (DEBORD, 1997, p.25).

Assim, a unidade que falta à vida, desfeita pelo fim de relações sociais concretas, é recuperada no plano das imagens, em que o objeto de desejo indispensável para minha realização e diferenciação da multidão é o mesmo almejado por milhões de pessoas que, como eu, procuram se diferenciar. Esse fetiche da mercadoria em sua forma mais ampla aliena o espectador e o retira da vida: "quanto mais ele contempla, menos vive; quanto mais aceita reconhecer-se nas imagens dominantes da necessidade, menos compreende sua própria existência e seu próprio desejo" (DEBORD, 1997, p.26). O espetáculo corresponde, portanto, à produção concreta da alienação:

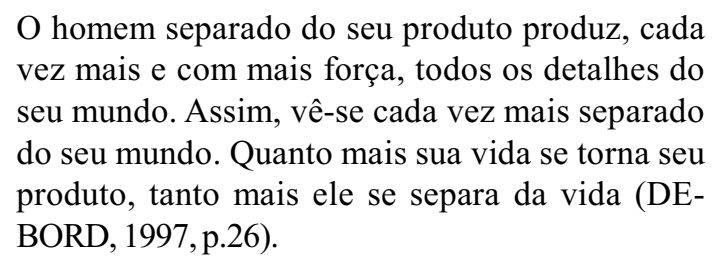

Contudo, embora mediada, a realidade não desaparece do mundo. Como explica o autor, "a realidade surge no espetáculo, e o espetáculo é real", e essa "dupla realidade" é a geradora de uma alienação recíproca que é ao mesmo tempo base e essência da sociedade do espetáculo. Há um processo de inversão do mundo uma vez que o real é visto e vivido através do espetáculo: 
"No mundo realmente invertido, a verdade é um momento do que é falso" (DEBORD, 1997, p.16). Apoiado no conceito marxista da falsa consciência, o autor tenta mostrar que essa inversão faz com que vejamos da sociedade apenas o que nela é irreal, partindo do princípio de que "o que aparece é falso, a verdade está oculta" (DEBORD, 1997, p.16). Nesse sentido, o que é visível da vida é apenas a sua negação, a sua falsificação, já que o espetáculo é a afirmação de toda vida humana como mera aparência e, portanto, o espetáculo é "a negação da vida que se tornou visível". Mas apesar de sua característica essencialmente falseadora, o espetáculo se apresenta ao mundo através de sua própria inversão, transformando-se numa positividade indiscutível: "o que aparece é bom, o que é bom aparece" (DEBORD, 1997, p.16).

Por tudo isso, o espetáculo é a forma atual e mais acabada de dominação do modo de produção capitalista, onde tudo começa e termina. Ele não é mais que a mesma dominação existente em todos os tempos sob nova forma, onde os meios de comunicação de massa são seus órgãos de dominação, seu instrumento de poder. Mas o espetáculo vai muito além da presença maciça dos meios de comunicação na condução da vida da sociedade. O espetáculo é o momento do esfacelamento da vida do indivíduo, do empobrecimento de suas relações sociais em detrimento do consumo passivo das imagens, daquilo que lhe falta após a expansão de sua sobrevivência pelo capital.

\section{A guerra como espetáculo}

Durante 43 dias o mundo assistiu ao espetáculo da guerra pós-moderna, de precisão cirúrgica e de aviões invisíveis que deixou um número de mortos estimado em 100 mil soldados iraquianos, sete mil civis, 30 mil kuwaitianos e 510 militares das forças de aproximadamente 30 países, comandadas pelos Estados Unidos (CORREIO BRAZILIENSE, 17 jan. 2001).

A cada minuto são criados novos conceitos-fetiche pelo espetáculo, não somente pelo seu principal meio de dominação - a mídia - mas por todos aqueles que estão inseridos no sistema espetacular, como governos de Estado, entidades econômicas e a própria academia. Neste pequeno trecho supracitado, podemos observar a rápida difusão de vários deles no tocante à guerra, e a partir do qual é possível levantar uma série de questões sobre o papel e o modo de veiculação de notícias sobre a guerra pelos meios de informação midiáticos.

Desde sempre, os combates empreendidos pelos Exércitos em todo o mundo receberam nomes a fim de destacá-los uns dos outros. No entanto, por muito tempo esses nomes permaneceram relacionados principalmente às características geográficas de onde se desenrolavam esses combates, 
como a guerra dos Cem ou dos Trinta anos, a Batalha de Stalingrado e a Campanha da Itália na II Guerra Mundial. No entanto, de uns tempos pra cá - isto é, no mundo espetacular - várias lutas passaram a receber nomes capazes trazer à mente das pessoas outras imagens que não apenas sua localização geográfica. Associados a valores morais, éticos ou ideológicos, esses nomes evocam uma série de sentimentos e ideais independentemente do curso dos acontecimentos, ou seja, das implicações e do real significado de uma guerra que, em última instância, nada mais é que aniquilação. Exemplo desses nomes-imagem - ou nomes-fetiche, se assim nos permitirem - são os nomes dados aos ataques empreendidos pelos EUA contra o Iraque, tanto na chamada primeira Guerra do Golfo (1991) quanto na que presenciamos mais recentemente (2003).

A primeira delas, empreendida pelo governo de George Bush (janeiro à março de 1991), foi batizada de Tempestade no Deserto, considerada a primeira superoperação de guerra e que viria a caracterizar o mundo pós-moderno, um marco do emprego da alta tecnologia tanto de destruição quanto de divulgação. Essa guerra consistiu em seis semanas de intensos bombardeios aéreos que ficaram conhecidos como ataques-cirúrgicos. Essa estrutura, jamais então vista, baseava-se em bombardeios desencadeados pelas forças de coalizão (cerca de 30 países) com a utilização das chamadas armas inteligentes: máquinas de guerra de avançada tecnologia e alta capacidade de destruição. As grandes vedetes dentre elas foram o jato "invisível" Stealth F-117A, incapaz de ser detectado pelos radares iraquianos, e os mísseis guiados por computador Tomahawk, com alto poder de precisão e destruição.

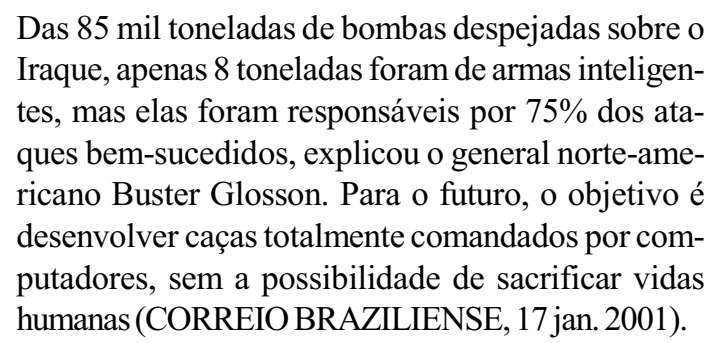

Os alvos consistiam basicamente em alvos militares e as armas com alto poder de precisão diminuíam as chances de erro, o que diminuiu consideravelmente o número de baixas do lado aliado, praticamente inexistente. Somente após a destruição das bases militares e do poder de resistência inimigo foi que a infantaria ${ }^{4}$ entrou efetivamente no território. Mas isso não quer dizer que não tenha havido morte.

\footnotetext{
${ }^{4}$ A infantaria é o grupamento militar que tem como característica essencial a aptidão para combates de solo, em todos os tipos de terreno e sob quaisquer condições meteorológicas, utilizando variados meios de transporte. Em razão disso, a infantaria poderá ter especializações das mais diversas: motorizada, blindada, pára-quedista, leve, de selva, de caatinga, de montanha, de guardas e de polícia (Disponível em: http://www.exercito.gov.br. Acesso em: 3 de novembro de 2008).
} 


\title{
HüANAs
}

Os ataques-cirúrgicos podem ter poupado a vida de homens das forças aliadas, mas provocaram pesadas baixas entre a população iraquiana, o que prova que até as cirurgias mais avançadas deixam seqüelas: o Iraque foi devastado e 137.510 pessoas foram mortas, entre soldados e civis.

Entretanto, a alta tecnologia militar não foi a única novidade dessa guerra. O que mais chamou atenção foi a utilização de modernos meios de captação e divulgação de imagens empregados pelos meios de comunicação, que proporcionaram ao mundo, pela primeira vez, assistir uma guerra ao vivo. As grandes empresas de comunicação investiram vultosas somas de dinheiro em tecnologia para que pudéssemos ver de nossas casas as luzes verdes das baterias antiaéreas iraquianas em meio à escuridão das noites de ataques.

\begin{abstract}
As imagens chegavam a Atlanta via satélite, enviadas por um equipamento que não dependia do fornecimento de energia elétrica no nono andar do hotel Al-Rashid, onde toda a imprensa estrangeira estava hospedada. Para conseguir entrar no Iraque com a antena, o repórter Peter Arnett teve de convencer os soldados de Saddam Hussein de que aquilo era um guarda-chuva - apesar de todo perfurado (CORREIO BRAZILIENSE, $17 \mathrm{jan} .2001)$.
\end{abstract}

Se por um lado o emprego maciço dessa tecnologia permitiu que o mundo assistisse a superioridade aliada sobre o inimigo, por outro deixou a coalizão aliada vulnerável, uma vez que foram expostos em rede mundial os chamados estragos colaterais do conflito, isto é, as falhas de precisão e os erros que causaram a morte de inúmeros civis iraquianos. $\mathrm{O}$ jornal $\mathrm{Wa}$ shington Post listou mais de 100 estruturas atingidas por engano. No erro mais grave, o bombardeio sobre o abrigo de refugiados Amiriyah, em Bagdá, fez 400 vítimas.

Após 43 dias de conflito os objetivos da guerra foram atingidos com a retirada das forças iraquianas do Kuwait - motivo do ataque - e a assinatura de um armistício. Como se tratava de uma luta pelo domínio do petróleo na região invadida, Saddam Hussein, chefe supremo do Iraque, continuou no poder com amplo apoio popular. Na época, a única medida tomada pelas Nações Unidas contra o Iraque foi um pesado embargo econômico que não alterou sua política interna. No entanto, em pouco mais de 10 anos, o mesmo ditador combatido por conta de questões econômicas e políticas transformouse num dos maiores inimigos das nações democráticas do mundo. 


\section{A renovação do espetáculo}

Durante anos houve uma concordância velada da comunidade internacional com relação a diversos atos contrários aos Direitos Humanos que tomavam lugar no Iraque. Também os inspetores de armas da ONU correram em busca dos armamentos proibidos de Saddam Hussein, sem concluir quase nenhuma inspeção, transformando o tal arsenal iraquiano num mistério. Porém, após os ataques empreendidos por um grupo terrorista afegão contra o símbolo comercial e financeiro dos EUA - que o espetáculo tornou conhecido como "O 11 de Setembro" - Saddam Hussein foi transformado em bodeexpiatório americano na luta contra o terrorismo. Assim, na madrugada do dia 20 de março de 2003, uma nova guerra contra o Iraque explodiu, não somente em território iraquiano, mas também nos aparelhos de televisão em todas as casas do mundo.

Resgatando o antigo preceito da guerra justa ${ }^{5}$, essa operação de guerra - batizada de Operação Liberdade Iraquiana - acrescentou uma nova categoria, contrária aos preceitos estabelecidos pelas convenções de guerra: a guerra preventiva. Esse plano doutrinário americano estabelecido no documento Estratégia de Segurança Nacional para os Estados Unidos é, mais que uma forma de defesa, um plano de fortalecimento do império americano ao declarar que "Como questão de bom senso e de autodefesa, os Estados Unidos tomarão medidas contra tais ameaças emergentes antes que elas tomem forma plenamente" (ABEX Jr, 2003, p.15). A partir da instituição dessa nova perspectiva estratégica, todo o mundo, principalmente o temido e tão citado Eixo do $\mathrm{Mal}^{6}$, torna-se vulnerável a um ataque de defesa americano dependendo da ameaça vislumbrada por seu governo, tendo em vista que:

[...] novos ataques preventivos podem ser decididos a qualquer momento, contra qualquer país, dado o poder militar incontrastável da superpotência, e dado o fato de que não há, no mundo, qualquer poder, nacional ou supranacional, capaz de oferecer resistência estratégica ao Exército estadunidense.

\footnotetext{
${ }_{5}^{5}$ Esse termo foi resgatado por Michael Walzer em 1977, após longos anos de declínio, e se refere essencialmente à realidade moral da guerra. Pode ser considerada justa uma guerra que desenvolve uma função natural, ou seja, quando luta contra algo considerado pior que a própria guerra, passando esta a ser vista como um mal necessário, servindo ao progresso da humanidade tanto em termos morais e civis quanto em termos técnico-científicos. Ela deve também a) ter como base razões políticas; b) ser decidida pela autoridade reconhecida; c) e ser precedida por uma declaração formal de guerra (WALZER, 1977).

${ }^{6}$ Potências regionais consideradas pelos EUA como de grande risco às Democracias Ocidentais. Inicialmente, faziam parte dessa lista além do Iraque, o Irã e a Coréia do Norte. Depois, Cuba, Líbia e Síria foram inseridos na listagem americana, cujo nome remete aos países do Eixo durante a Segunda Guerra Mundial (Alemanha, Japão e Itália).
} 


\title{
HUMANAS
}

[...] Isso implica, necessariamente, a total abolição de qualquer ordem internacional (ARBEX Jr, 2003, p.16).

Como bem argumenta William Waack:

\begin{abstract}
As decisões importantes de cada país nascem não só dos seus interesses declarados e manifestados econômicos, políticos, geopolíticos. Nascem, sobretudo, de visões de mundo e de crenças, dos traumas coletivos e da interpretação da realidade internacional. No caso dos Estados Unidos pós-atentados de 11 de setembro, as principais conseqüências das tragédias de Nova York e Washington foram o reforço à idéia, já desenvolvida anteriormente por thinktanks republicanos, de que as causas do terrorismo teriam de ser eliminadas pela mudança da forma de pensar dos outros (WAACK, 2006, p. 467).
\end{abstract}

Assim, numa série de novos ataques-cirúrgicos, a tática inicial aliada que dessa vez contou apenas com a participação de EUA e Inglaterra, que desencadearam a guerra mesmo sem o aval da ONU - era de promover ataques seletivos, que consistiam em ataques a postos iraquianos estratégicos, localizados principalmente no centro de Bagdá, determinados com vistas a aniquilar o mais rapidamente possível as lideranças iraquianas: leia-se matar Saddam Hussein, seus filhos e outros líderes - a fim de enfraquecer a resistência iraquiana.

O espantoso aperfeiçoamento da tecnologia de captação e transmissão de imagens via satélite nos permitiu admirar as imensas explosões que iluminavam o céu de Bagdá, seguidas do fogo e da fumaça decorrentes dos incêndios provocados pelos ataques. Como na guerra anterior, os meios de comunicação tiveram papel de destaque neste novo espetáculo, porém, podemos constatar que sua atuação foi bem mais perniciosa que na guerra anterior. Durante os bombardeios incessantes, a televisão mostrou uma guerra sem mortos (números iraquianos não são gente) e, portanto, sem sofrimento, o que garantiu altos índices de aprovação à guerra entre a população estadunidense que não viu seus filhos sendo sacrificados como na guerra do Vietnã. Mas isso não significa que não houve baixas no lado aliado, principalmente quando a infantaria passou a enfrentar a resistência iraquiana. Do lado de fora das máquinas de guerras, o que se viu foi o despreparo e o medo de jovens estadunidenses ao enfrentar uma população já acostumada a anos de privação.

Quando a mídia mostrava imagens da força e superioridade americana em meio à inevitabilidade da guerra, como as dos filhos de Saddam Hussein mortos, essas imagens eram amplamente divulgadas por todos os veículos de comunicação como uma espécie de intimidação americana ao resto do mundo. 
No entanto, quando essas imagens mostravam americanos presos pela resistência iraquiana, o mundo democrático as condenava como violação dos direitos dos prisioneiros de guerra. Como entender e jogar de acordo com as regras um jogo em que elas não são as mesmas para ambos os lados? Como afirma Debord (1997a, p.165):

O discurso espetacular cala evidentemente, além de tudo aquilo que é propriamente secreto, tudo aquilo que não lhe convém. Daquilo que mostra ele isola sempre o meio, o passado, as intenções, as consequências. É, portanto, totalmente ilógico. O discurso mostrado pelo espetáculo não deixa lugar para a resposta.

O segredo generalizado mantém-se por detrás do espetáculo, como o complemento decisivo daquilo que ele mostra e, se aprofundamos mais as coisas, ele é a sua mais importante operação. Os reais motivos da guerra, a luta pelo controle do petróleo no mundo, esconderam-se atrás de pretextos capazes de engrandecer o Destino Manifesto da nação norte-americana como a luta contra o terrorismo no mundo, que consistia em destruir o arsenal iraquiano de armas de destruição em massa e livrar o povo do Iraque de um ditador sanguinário como Saddam Hussein, levando a democracia a todos os povos.

Em seus Comentários sobre a sociedade do espetáculo (1997a), Debord destaca a necessidade da ideologia democrática em criar um inimigo. Durante a Guerra Fria (1949-1989) esse inimigo era de fácil identificação: o Comunismo. Porém, o mundo dominado por uma única superpotência produziu um inimigo multifacetado: o terrorismo. Segundo Debord, a democracia quer ser julgada pelos seus inimigos e não por seus resultados. Uma vez que o inimigo é criado pelo Estado, sua história é aplicada como método educativo:

\begin{abstract}
As populações espectadoras não podem certamente saber tudo sobre o terrorismo, mas podem sempre saber a esse respeito o suficiente para serem persuadidas de que, comparado ao terrorismo, tudo o resto deverá parecer-lhes mais aceitável, em todo o caso mais racional e mais democrático (DEBORD, 1997a, p.165).
\end{abstract}

Por isso, o autor considera a atual ideologia da democracia como a "liberdade ditatorial do Mercado, moderada pelo reconhecimento dos Direitos do Homem espectador" (DEBORD, 1997, p.166). Suas afirmações permanecem atuais quando as aplicamos à guerra de que estamos tratando. 
Sob pretextos de democracia e liberdade, foram poucas as vozes que se levantaram no Ocidente com comentários críticos sobre o significado e as consequências do extraordinário acontecimento midiático da guerra, o que prova por si mesmo o progresso da técnica espetacular. Debord destacou o caso do fim da Guerra Fria, no qual o que se registrou foi a aparência de um fato de natureza geológica: considerou-se o fenômeno suficientemente compreendido ao reter apenas um sinal tão elementar como a queda do muro de Berlim, ignorando-se os discutíveis sinais democráticos (DEBORD, 1997, p.170). Assim também na "atual" guerra a impressão que se tem é que o mundo contentou-se com a captura do ditador Iraquiano como símbolo do seu final (que, de fato, ainda não houve, já que tropas de vários países do mundo permanecem em território iraquiano). O que fazer com ele depois de capturado, onde e de que forma julgá-lo, onde estão suas armas de destruição em massa, como dar continuidade ao processo de democratização do Iraque são questões essenciais que colocam em xeque as justificativas e os preceitos "democráticos" estadunidenses, mas que, no entanto, foram e ainda são questões pouco discutidas pelos meios de comunicação.

O espetáculo ilógico que assistimos e continuamos a ver se desenrolar no Iraque parece ter chegado ao final sem uma conclusão, mas são poucos aqueles que se dão conta disso. Saddam Hussein foi capturado e morto ${ }^{7}$ e, ainda hoje, busca-se instalar uma pretensa democracia no Iraque. Contudo, o tal arsenal de destruição em massa - principal pretexto da guerra - até agora não foi encontrado. E que será feito da estrutura destruída pela guerra: quem a governará, quem a reconstruirá? O espetáculo que dominou o mundo continua sendo o mesmo apresentado por Debord:

A primeira intenção da dominação espetacular era fazer desaparecer o conhecimento histórico em geral; e em primeiro lugar quase todas as informações e todos os comentários razoáveis sobre o mais recente passado. Uma evidência tão flagrante não necessita ser explicada. O espetáculo organiza com maestria a ignorância do que acontece e, logo em seguida, o esquecimento daquilo que pôde apesar de tudo tornar-se conhecido. O mais importante é o mais escondido. O movimento da demonstração espetacular prova-se simplesmente andando à roda:

\footnotetext{
7 Saddam Hussein foi capturado pelas forças militares estadunidenses em 30 de junho de 2004 , entregue ao governo iraquiano que promoveu seu julgamento em um Tribunal Especial. O expresidente foi acusado de violações dos Direitos Humanos durante o seu governo e foi condenado à morte por enforcamento pelo assassinato de 148 homens, predominantemente xiitas, na cidade iraquiana de Dujail, em 1982.
} 
voltando, repetindo-se, afirmando continuamente sobre o único terreno onde reside doravante aquilo que pode afirmar-se publicamente, e fazer-se acreditar, pois que é disso somente que todo o mundo será testemunha. Aquilo de que o espetáculo pode deixar de falar durante três dias é como se não existisse. Pois ele fala, então, de outra coisa qualquer e é isso que, portanto, a partir daí, em suma, existe. As consequências práticas, como se vê, são imensas (DEBORD, 1997a, p.165).

Segundo Debord, a sociedade modernizada ao estágio do espetacular integrado $^{8}$ se caracteriza pelo efeito combinado de cinco traços principais: a renovação tecnológica incessante; a fusão econômico-estatal; o segredo generalizado; o falso sem réplica; um presente perpétuo. Todos os traços podem ser encontrados na guerra atual, apropriada pelo espetáculo. A constante inovação tecnológica é constitutiva da própria sociedade capitalista, entretanto, a diferença é que agora se dedica ao reforço da autoridade espetacular. A fusão econômico-estatal é uma das tendências mais fortes deste século e pode ser vista por trás dos reais objetivos da guerra e a aliança formada entre estes dois poderes, a Economia e o Estado, assegura os maiores benefícios para ambos. Os três últimos traços, conclui Debord, "são os efeitos diretos da dominação, no seu estado integrado", sem a necessidade de maiores explicações, pois são visíveis para todos aqueles que procuram pensar para além do espetáculo.

\section{Considerações finais}

Cabe aqui uma ressalva. Não é somente nos meios de comunicação que o espetáculo se apresenta, mas é nele onde podemos visualizar com mais clareza seu funcionamento e seus efeitos. Na maioria das vezes, como apontou Debord, entramos numa discussão vazia sobre o espetáculo, numa falácia que aborda apenas os seus grandes meios, seus recursos técnicos, para nada dizer a respeito de sua utilização. Assim, acaba-se responsabilizando os meios pelo espetáculo, como se a "mídia" fosse sua principal e única responsável. Ou, noutras vezes, transfere-se essa responsabilidade ao público, como se ele fosse culpado pelo lixo diário exibido diariamente devido "à sua tendência de entrega total aos exageros da mídia" - esses excessos considerados como sinônimo de espetáculo - quando, na verdade isso não passa de uma "convergência espetacular querida com uma notável tenacidade" (DEBORD, 1997a, p.170).

\footnotetext{
${ }^{8}$ Estágio no qual se encontra a sociedade atual, uma vez que a antiga separação do mundo em dois blocos ideológicos rivais foi superada (o espetacular concentrado e o espetacular difuso) e o espetáculo tomou uma única forma: o espetacular integrado.
} 
O espetáculo está aí, presente e ativo, dominador, e sua continuidade não se deve ao aperfeiçoamento de sua instrumentação, dos mais modernos meios de comunicação que alcançam o mundo todo em segundos, da televisão ou da Internet. Deve-se, sim, ao fato de que a dominação espetacular tenha sido capaz de criar uma geração inteira submetida às suas leis. A saída para essa situação? Difícil imaginar. O próprio Debord a dificulta, uma vez que nos mostra que o discurso do espetáculo não deixa espaço para respostas, tampouco para contradizê-lo. Para ele, é somente através da leitura que podemos escapar ao espetáculo. Por exigir um verdadeiro julgamento a cada linha e já que a conversação está quase morta - "e em breve também estarão muitos daqueles que sabiam falar" - só ela pode dar acesso à vasta experiência humana antiespetacular.

\section{Referências bibliográficas}

ARBEX Jr, J. "George W, mas pode chamar de Adolf H". Caros Amigos, São Paulo, Especial nº 17, p.16-17, jun. 2003.

DEBORD, G. A sociedade do espetáculo. Rio de Janeiro: Contraponto, 1997.

DEBORD, G. Comentários sobre a sociedade do espetáculo. In: DEBORD, G. A sociedade do espetáculo. Rio de Janeiro: Contraponto, 1997a.

ECO, U. Apocalípticos e integrados. São Paulo: Perspectiva, 1993.

JAMESON, F. Pós-modernidade e sociedade de consumo. In: Novos estudos Cebrap, ${ }^{\circ}$ 12, jun. 1985.

WAACK, W. Guerras do Golfo. In MAGNOLI, D. (org.). História das guerras. 3.ed. São Paulo: Contexto, 2006.

CORREIO BRAZILIENSE. 10 anos da guerra do Golfo. Brasília, DF, 17 jan. 2001. Disponível em: http://www2.correioweb.com.br/cw/2001-01-17/ cab_7686.htm Acesso em: 04 de janeiro de 2004. 